DOI: $10.15593 / 2224-9354 / 2018.4 .21$

УДК 621:005.93-047.43

\title{
А.Г. Ташкинов
}

\section{РАЗРАБОТКА МЕТОДА ОЦЕНКИ КОНКУРЕНТОСПОСОБНОСТИ ПРОИЗВОДСТВЕННО-ЭКОНОМИЧЕСКОЙ СИСТЕМЫ МАШИНОСТРОИТЕЛЬНОГО ПРЕДПРИЯТИЯ}

\begin{abstract}
В настоящее время вопросы технологии управления и методы ее оценки становятся объектами пристального внимания для руководства машиностроительных предприятий. Российские машиностроительные предприятия на современном этапе развития осуществляют интенсивный поиск решения экономических проблем и результативных способов увеличения прибыли хозяйствующих субъектов в конкурентной среде. Решение задачи обеспечения конкурентоспособности хозяйствующих субъектов в условиях динамичной экономики приобретает особую актуальность. С учетом сказанного принципиальным путем решения этой проблемы является создание и реализация гибких производственно-экономических систем. В наибольшей степени таким параметрам отвечает интегрированная технология управления развитием производственно-экономической системы. В статье показано, что повышение конкурентоспособности машиностроительных предприятий возможно за счет разработки и последующего внедрения и оценки интегрированной технологии управления развитием. Для эффеективного управления процессом преобразований автором разработана интегрированная технология управления развитием производственно-экономической системы машиностроительного предприятия. В статье детально описан авторский метод оценки экономической эффективности интегрированной технологии управления развитием, охарактеризованы его основные преимущества. С целью оценки экономической эффективности интегрированной технологии управления развитием предложена система специфических показателей. Оценку экономической эффеективности предлагается проводить с помощью специфических показателей в соответствии с разработанным методом. Предложенный метод оценки был применен для решения практических задач на машиностроительных предприятиях г. Перми. Разработанный автором метод помогает определить текущее состояние основных факторов предприятия, способных обеспечить реализацию инновационных идей и выпуск конкурентоспособной продукции и принять стратегические решения, способствующие повышению конкурентоспособности машиностроительных предприятий.

Ключевые слова: интегрированная технология управления развитием производственноэкономической системы, конкурентоспособность машиностроительных предприятий, принципы ресурсно-процессного подхода, экономическая эфрфрективность.
\end{abstract}

Одним из основополагающих принципов разработанной автором интегрированной технологии управления развитием производственно-экономической системы является принцип экономичности и эффективности. Он предполагает эффективное расходование ресурсов в процессе управления производством, разработку соответствующей технологии управления и т.д. Из данного принципа вытекают определенные требования как к производственной системе в целом, так и к интегрированной технологии управления развитием

(C) Ташкинов А.Г., 2018

Ташкинов Алексей Григорьевич - начальник Координационно-методического центра внедрения цифровой экономики АО «Пермский завод «Машиностроитель», соискатель кафедры менеджмента и маркетинга ФГБОУ ВО «Пермский национальный исследовательский политехнический университет», e-mail: alekss.perm@gmail.com. 
производственно-экономической системы. Оценка экономической эффективности интегрированной технологии управления развитием производственноэкономической системы является необходимым условием подтверждения факта конкурентоспособности и эффективности машиностроительного предприятия. На основе повышения экономической эффективности своей деятельности предприятие приобретает конкурентные преимущества, опираясь на которые оно определяет стратегию своего развития. В современных условиях успешно развиваются те предприятия, которые используют гибкую технологию управления развитием производственно-экономической системы в качестве стратегического ресурса.

По мнению М. Портера, конкурентное преимущество предприятия может определять любая из применяемого набора технологий управления: от простых административных процедур до научных достижений, используемых при проектировании и производстве продукции. При этом любая деятельность предприятия, включая стратегическое планирование, маркетинг, сбыт, производство, кадры, закупку, распределение, финансирование, может рассматриваться как использование технологий управления, которые должны создавать конкурентное преимущество предприятия [1].

Оценка экономической эффективности применяемых технологий управления на всех уровнях - крайне актуальная задача для машиностроительных предприятий. Оценка экономической эффективности интегрированной технологии управления развитием производственно-экономической системы может обеспечить решение следующих вопросов:

- определить экономический эффект от внедрения разработанных и внедренных инноваций;

- оценить влияние производственно-хозяйственной деятельности на эффективность работы предприятия в целом;

- оптимизировать выбор правильных направлений развития производственно-экономической системы (ПЭС);

- актуализировать проведение дальнейших научных разработок.

Отметим, что в исследованиях, посвященных проблеме выбора метода оценки экономической эффективности ПЭС, достаточно часто используется термин «технология управления». При этом подчеркивается, что исследование и систематизация спектра подходов к трактовке понятия «технология управления», встречающихся у отечественных и зарубежных авторов, свидетельствует о существовании различных определений данного термина. В этой связи проведем анализ действующих определений, отражающих сущностные аспекты понятия «технология управления». В представленных в табл. 1 определениях просматриваются общие подходы к определению понятия «технология управления», которые создают необходимые предпосылки и условия для принятия решений в рамках каждого процесса управления, которые бла- 
гополучно доводят реализацию управленческих функций до конца, а значит, и весь управленческий цикл до логического завершения. В определениях, представленных в табл. 1, выделены основные составляющее технологии управления, на основе которых эти определения сформулированы.

Таблица 1

Подходы к определению понятия «технология управления»

\begin{tabular}{|c|c|c|}
\hline $\begin{array}{l}\text { № } \\
\Pi / \Pi\end{array}$ & Автор & Определение понятия \\
\hline 1 & Акатов Н.Б. [2] & $\begin{array}{l}\text { Технология управления - регламент выполнения процесса, } \\
\text { включающий подробный и всесторонний анализ деятельно- } \\
\text { сти организации, определение уровня зрелости менеджмента } \\
\text { и выявление наиболее важных областей для улучшения }\end{array}$ \\
\hline 2 & Герасимов К.Б. [3] & $\begin{array}{l}\text { Технология управления - совокупность типовых операций } \\
\text { деятельности, реализуемой в рамках какой-либо части управ- } \\
\text { ления процессами предприятия с помощью последовательно- } \\
\text { сти процедур для эффективной реализации этой деятельности }\end{array}$ \\
\hline 3 & $\begin{array}{l}\text { Молодчик А.В., } \\
\text { Молодчик М.А. [4] }\end{array}$ & $\begin{array}{l}\text { Технология управления - система, включающая взаимодей- } \\
\text { ствие людей, материальных, финансовых и информационных } \\
\text { ресурсов, а также взаимодействие с другими системами на } \\
\text { рынке продавцов и покупателей }\end{array}$ \\
\hline 4 & Пригожин А.И. [5] & $\begin{array}{l}\text { Технология управления - четкий алгоритм действий по регу- } \\
\text { лированию бизнес-процессов }\end{array}$ \\
\hline 5 & $\begin{array}{l}\text { Тис Д. Дж., } \\
\text { Пизано Г., } \\
\text { Шуен Э. [6] }\end{array}$ & $\begin{array}{l}\text { Технология управления (рутины) - это регулярно повторяю- } \\
\text { щиеся процедуры ведения деятельности, понятие, объеди- } \\
\text { няющее умения, организацию и технологии в силу их практи- } \\
\text { ческой неразличимости }\end{array}$ \\
\hline
\end{tabular}

Основными составляющими технологий управления являются процедуры, совокупность типовых операций, действия и приемы, расположенные в определенной последовательности. Большинство определений технологии управления способствуют решению функциональных задач управления, которые направлены на поддержание функционирования и развития различных сторон деятельности предприятия.

В приведенных в табл. 1 определениях просматриваются некоторые расхождения. Нами предлагается конкретизировать понятие интегрированной технологии управления развитием, которое рассматривает управление с позиции качественного преобразования ПЭС в целом или с привнесением в нее конкурентных преимуществ, новых элементов и связей.

В связи с этим под интегрированной технологией управления развитием производственно-экономической системы машиностроительного предприятия (ИТУРпэсмп) понимается гибкая система принятия управленческих решений, обеспечивающая получение конкурентных преимуществ, новых элементов и связей и обладающая способностью адаптироваться к изменяюшимся условиям. 
Для повышения конкурентоспособности предприятий руководству рекомендуется использовать описанную в работе [14] ИТУРпэсмп, которая учитывает специфику высокотехнологичных машиностроительных предприятий, базируется на принципах ресурсно-процессного подхода, обеспечивает осуществление организационных изменений как в управлении производством, так и организации экономики производственных процессов. И эта система, чтобы не утрачивать релевантность, в свою очередь должна постоянно совершенствоваться.

В настоящем исследовании выделена группа высокотехнологичных машиностроительных предприятий г. Перми авиационной промышленности. Это наиболее высокотехнологичная и наукоемкая отрасль, одна из передовых, относительно стабильно и динамично развивающихся отраслей промышленности. Предприятия одновременно являются и наиболее инновационно активными.

Для данной отрасли характерны свои специфические особенности:

- сильная зависимость от импортных комплектующих для сборки изделий;

- длительный цикл разработки, производство и эксплуатации изделий;

- мелкосерийное и единичное производство;

- большая трудоемкость изделий, значительный объем кооперации, затрагивающей не только высокотехнологичные предприятия, но и предприятия других отраслей;

- высокие требования к качеству и надежности изделий, что определяет большой объем испытаний и контрольных проверок при производстве техники.

В настоящее время на машиностроительных предприятиях авиационной отрасли преобладает предметная специализация цехов и участков. Эта такая форма специализации, при которой в одном цехе сосредотачивается изготовление разнотипных деталей одного или нескольких однотипных изделий или сборочных единиц. В большинстве случаев изготовление изделий при этом завершается сборкой в том же цехе.

Предметная замкнутая форма специализации является лучшей, как правило, для формирования цехов в условиях массового производства. В условиях же мелкосерийного и особенно единичного производства не создаются условия для эффективного использования высокопроизводительного оборудования. Внедрение современного оборудования требует перевода организации производства предприятий на подетально-групповую или технологическую форму специализации.

Эффективность нами определяется как сопоставление полученного фактического результата деятельности к использованным для его достижения ресурсам [7]. Следовательно, понятие «экономическая эффективность» представляет собой совокупную результативность субъекта хозяйствования по 
всем направлениям деятельности [8]. Таким образом, эффективность - это экономическая категория, выражающая результативность ее деятельности.

Под развитием производственной системы в работе понимается процесс изменения количественно-качественных характеристик системы с достижением ее целевого состояния при реализации портфеля проектов, объединенных конкретной целью, каждый из которых направлен на решение определенных задач. Развитие производственной системы в рамках настоящей работы рассматривается как составная часть внутреннего развития компании и включает в себя: внедрение управленческих технологий, выстраивание бизнес-процессов, внедрение портфеля проектов $[9,10]$.

На основе изученных работ по оценке экономической эффективности ПЭС $[7,8,11,12,13]$ разработан авторский метод.

Метод оценки экономической эффективности ИТУРпэсмп разработан на подсистемном уровне, выбор которого основан на определении и учете параметров факторов внешней и внутренней среды, формирующих перспективы развития и направления повышения конкурентоспособности и экономической эффективности, а также последовательность этапов ее оценки от внедрения отдельных составляющих ИТУРпэсмп.

Схема разработанного метода оценки экономической эффективности ИТУРпэсмп представлена на рисунке.

Первый этап метода заключается в системном определении формирования агрегированной группы факторов внешней и внутренней среды ИТУРпэсмп, анализ и оценка воздействий которых осуществляется посредством постоянного мониторинга и оперативной обработки консолидированной аналитической информации. Внешние и внутренние факторы систематизированы нами в работе [14], что позволяет руководству получать необходимую информацию для определения возможных направлений с целью повышения уровня конкурентоспособности предприятий. И на основании оценки текущего и прогнозируемого уровня их воздействия позволяет определять долгосрочные, среднесрочные и текущие цели и задачи хозяйственной деятельности с учетом возможных колебаний и изменений определенностей, а также осуществлять необходимые корректирующие мероприятия с целью получения конкурентных преимуществ.

Bторым этапом является систематизация показателей высокотехнологичного машиностроительного предприятия, оказывающих влияние на оценку конкурентоспособности ПЭС (по снижению уровня дефектной продукции, затратам критического пути производства, качеству и уровню затрат и др.), обеспечивающих долгосрочную эффективность производственно-хозяйственной деятельности. Особое место на этом этапе отводится внутренним аспектам управления машиностроительным предприятием, охватывающим финансовую, экономическую, производственную и материально-техническую сферы предприятия. 


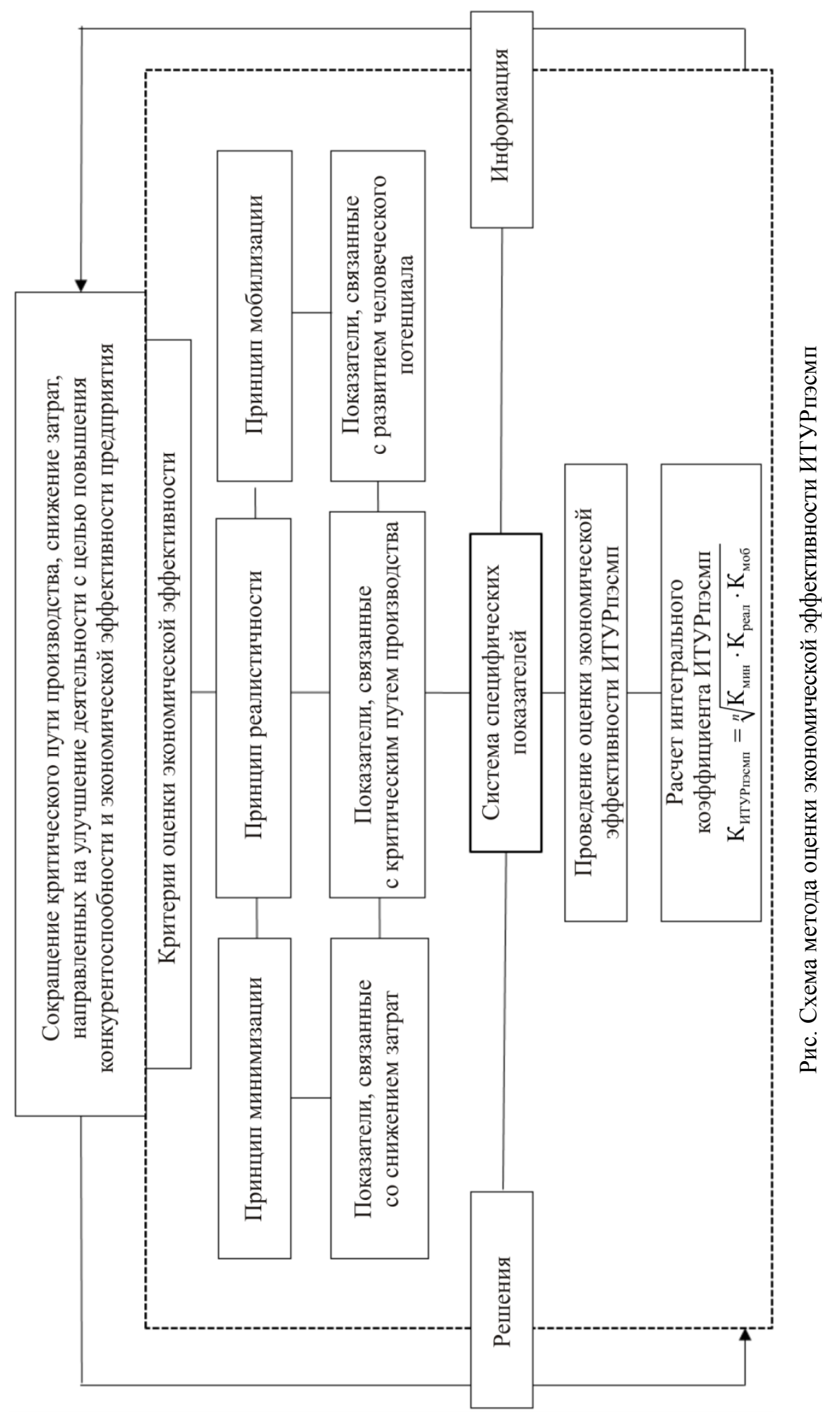


На третьем этапе конкретизируются количественные и качественные параметры (объем производства, степень использования производственных ресурсов, качество производимой продукции, длительность производственного цикла, время выполнения заказа, размер производственных запасов) ожидаемого повышения экономической эффективности, полученные в результате внедрения отдельных составляющих ИТУРпэсмп. Эти параметры ввиду отраслевой специфики, специализации и типа производства определяются для каждого конкретного машиностроительного предприятия отдельно.

На четвертом этапе осуществляется разработка системы специфических показателей оценки экономической эффективности ИТУРпэсмп, отвечающей целям и задачам обеспечения конкурентоспособности и повышения экономической эффективности машиностроительного предприятия.

Принципиальное значение имеет выбор критериев оценки экономической эффективности. Исходя из данного положения сделан выбор в пользу специфических показателей, которые определяются целевыми параметрами при проектировании ПЭС и условиями определения конкурентоспособности и повышения экономической эффективности предприятия на основе принципов ресурсно-процессного подхода. С учетом этого для каждого принципа выделена группа специфических показателей. Так, например, для принципа минимизации определены специфические показатели, связанные со снижением затрат. Принцип реалистичности определяется показателями критического пути производства. Принцип мобилизации оценивается показателями, связанными с развитием человеческого потенциала.

Исходя из данной особенности в табл. 2 осуществлен выбор в пользу специфических показателей, которые определяются целевыми параметрами при проектировании ПЭС и условиями определения конкурентоспособности и повышения экономической эффективности предприятия на основе предложенных принципов ресурсно-процессного подхода [14].

Таблица 2

Специфические показатели, оказывающие влияние на оценку экономической эффективности ИТУРпэсмп

\begin{tabular}{|c|l|l|}
\hline $\begin{array}{c}\text { № } \\
\text { п/п }\end{array}$ & \multicolumn{1}{|c|}{$\begin{array}{c}\text { Специфический } \\
\text { показатель }\end{array}$} & \multicolumn{1}{|c|}{ Эффект от внедрения ИТУРпэсмп } \\
\hline 1 & \multicolumn{1}{|c|}{ Специфические показатели оценки принципа минимизации } \\
\hline 1.1 & $\begin{array}{l}\text { Коэффициент снижения } \\
\text { уровня дефектной продукции }\end{array}$ & $\begin{array}{l}\text { Создание ценности для клиента, выпуск качественной про- } \\
\text { дукии и др. }\end{array}$ \\
\hline 1.2 & $\begin{array}{l}\text { Коэффициент снижения } \\
\text { производственных потерь }\end{array}$ & $\begin{array}{l}\text { Ожидаемые результаты за счет сокращения различных ви- } \\
\text { дов потерь в производственных процессах, непрерывных } \\
\text { улучшений и др. }\end{array}$ \\
\hline 1.3 & $\begin{array}{l}\text { Коэффициент роста } \\
\text { производительности труда }\end{array}$ & $\begin{array}{l}\text { Первоочередное устранение потерь в производственных } \\
\text { прцессах, т.е. повышение производительности труда }\end{array}$ \\
\hline
\end{tabular}


Окончание табл. 2

\begin{tabular}{|c|c|c|}
\hline $\begin{array}{l}\text { № } \\
\text { ח/п }\end{array}$ & $\begin{array}{l}\text { Специфический } \\
\text { показатель }\end{array}$ & Эффект от внедрения ИТУРпэсмп \\
\hline 2 & \multicolumn{2}{|c|}{ Спецฺифические показатели оченки принцииа реалистичности } \\
\hline 2.1 & $\begin{array}{l}\text { Коэффициент критического } \\
\text { пути производства }\end{array}$ & $\begin{array}{l}\text { Сокращение времени переналадки, выполнения заказов, что } \\
\text { положительно скажется на репутации компании и количе- } \\
\text { стве заказов }\end{array}$ \\
\hline 2.2 & $\begin{array}{l}\text { Коэффициент затрат } \\
\text { критического пути } \\
\text { производства }\end{array}$ & $\begin{array}{l}\text { Уменьшение затрат на производство единицы продукции; } \\
\text { снижение затрат на хранение сырья, полуфабрикатов и } \\
\text { продукции; повышение качества выполненных работ }\end{array}$ \\
\hline 2.3 & $\begin{array}{l}\text { Коэффициент загрузки } \\
\text { оборудования }\end{array}$ & $\begin{array}{l}\text { Снижение потребности в излишнем оборудовании, инстру- } \\
\text { ментах, инвентаре вследствие повышения эффективности } \\
\text { производственных процессов; снижение потребности в } \\
\text { обновлении оборудования, инструментов, инвентаря вслед- } \\
\text { ствие снижения его износа за счет исключения перепроиз- } \\
\text { водства }\end{array}$ \\
\hline 3 & \multicolumn{2}{|c|}{ Спецчифические показатели очченки принцчипа мобилизачии } \\
\hline 3.1 & $\begin{array}{l}\text { Коэффициент стабильности } \\
\text { ключевого персонала }\end{array}$ & $\begin{array}{l}\text { Обеспечение стабильности ключевого персонала в целом } \\
\text { позволяет улучшать работу предприятия }\end{array}$ \\
\hline 3.2 & $\begin{array}{l}\text { Коэффициент патентной } \\
\text { обеспеченности }\end{array}$ & $\begin{array}{l}\text { Формирование дополнительного источника выручки через } \\
\text { создание ноу-хау, программного обеспечения, центров } \\
\text { компетенций и баз знаний по внедрению инноваций }\end{array}$ \\
\hline 3.3 & $\begin{array}{l}\text { Коэффициент повышения } \\
\text { квалификации персонала }\end{array}$ & $\begin{array}{l}\text { Формирование дополнительного источника выручки за счет } \\
\text { обучения персонала новым методам управления производ- } \\
\text { ством, организации курсов, семинаров, повышения квали- } \\
\text { фикации руководителей, специалистов и служащих }\end{array}$ \\
\hline
\end{tabular}

Учитывая данные обстоятельства, для выбора наиболее значимых критериев в работе использованы методы экономического анализа, экспертных оценок, анкетирования, рассмотренных в работе [15].

Рассмотрим более подробно пятый этап, в части оценки экономической эффективности от внедрения отдельных составляющих ИТУРпэсмп. Определение экономической эффективности от внедрения ИТУРпэсмп производится в виде оценки специфических показателей, сгруппированных по критериям оценки, снижения затрат, критического пути производства и развития человеческого потенциала.

Оценку экономической эффективности предлагается проводить экспертным методом. После определения специфических показателей, влияющих на экономическую эффективность ИТУРпэсмп, экспертным путем были определены весовые коэффициенты каждой группы показателей и каждого показателя в группе с учетом рекомендаций из числа высококвалифицированных специалистов:

- специфическим показателям оценки принципа минимизации был присвоен удельный вес 0,33 ;

- специфическим показателям оценки принципа реалистичности был присвоен удельный вес 0,33 ;

- специфическим показателям оценки принципа мобилизации был присвоен удельный вес 0,34 . 
Степень согласованности мнений экспертов по поводу приоритетности влияния специфических показателей на экономическую эффективность ИТУРпэсмп была определена с помощью коэффициента конкордации Кендалла:

$$
W=9 S /[m 2(n 3-n)],
$$

где $S$ - сумма квадратов отклонений рангов каждого объекта экспертизы от средней арифметической величины рангов; $n$ - количество экспертов; $m$ - число объектов экспертизы. Значение коэффициента конкордации изменяется в пределах от 0 до 1. В данном исследовании значение составило 0,83 .

Следует отметить, что выбор подхода к формированию базовых значений по отдельным специфическим показателям оценки экономической эффективности осуществляется индивидуально в каждом конкретном случае с учетом рекомендаций экспертов.

Оценку экономической эффективности ИТУРпэсмп предлагается проводить с помощью специфических показателей в соответствии с моделью, отраженных в табл. 3.

Таблица 3

Специфические показатели оценки экономической эффективности ИТУРпэсмп

\begin{tabular}{|c|c|c|}
\hline $\begin{array}{c}\text { № } \\
\Pi / \Pi\end{array}$ & Специфический показатель & Способ расчета \\
\hline 1 & \multicolumn{2}{|c|}{ Специффические показатели оценки принциипа минимизации } \\
\hline 1.1 & Коэффициент снижения уровня дефектной продукции & $\mathrm{K}_{\text {деф.пр }}=\mathrm{K}_{\text {деф.пр }} / \mathrm{K}_{\text {общ.пр }}$ \\
\hline 1.2 & Коэффициент снижения производственных потерь & $\mathrm{K}_{\text {пот }}=\mathrm{K}_{\text {пот.п }} / \mathrm{K}_{\text {пот.ф }}$ \\
\hline 1.3 & Коэффициент роста производительности труда & $\mathrm{K}_{\Pi \mathrm{T}}=\Pi \mathrm{T}_{\phi} / \Pi \mathrm{T}_{\Pi}$ \\
\hline 2 & \multicolumn{2}{|c|}{ Специчфические показатели оченки принципа реалистичности } \\
\hline 2.1 & Коэффициент критического пути производства & $\mathrm{K}_{\text {Кпп }}=$ Ож.кпп / Тек.Кпп \\
\hline 2.2 & Коэффициент затрат критического пути производства & $\mathrm{K}_{\text {затр }}=$ Ож. \\
\hline 2.3 & Коэффициент загрузки оборудования & $K_{3.06}=K_{\text {факт. } 3.06} / K_{\text {норм.3.об }}$ \\
\hline 3 & \multicolumn{2}{|c|}{ Специфические показатели оченки принципа мобилизачии } \\
\hline 3.1 & Коэффициент стабильности ключевого персонала & $\mathrm{K}_{\text {перс }}=\mathrm{Ч}_{\text {общ }} / \mathrm{K}_{\text {перс }}$ \\
\hline 3.2 & Коэффициент патентной обеспеченности & $\mathrm{K}_{\text {пат }}=\mathrm{K}_{\text {пат.п }} / \mathrm{K}_{\text {пат.ф. }}$ \\
\hline 3.3 & Коэффициент повышения квалификации персонала & $\mathrm{K}_{\text {проф }}=\mathrm{K}_{\text {осв.проф }} / \mathrm{Ч}_{\text {общ }}$ \\
\hline
\end{tabular}

Сумма значений представленных в табл. 3 специфических показателей позволяет рассчитать интегральный коэффициент ИТУРпэсмп с учетом весового показателя, который рассчитывается следующим образом:

$$
\mathrm{K}_{\text {ИТУРпэмпп }}=1 i \cdot \mathrm{K}_{\text {мин }}+2 i \cdot \mathrm{K}_{\text {реал }}+3 i \cdot \mathrm{K}_{\text {моб }},
$$

где $i$ - весовая значимость показателя.

В качестве критериев оценки экономической эффективности принята формула (3) для расчета интегрального коэффициента ИТУРпэсмп:

$$
\mathrm{K}_{\text {ИТУРпсмп }}=\sqrt[n]{\mathrm{K}_{\text {мин }} \cdot \mathrm{K}_{\text {реал }} \cdot \mathrm{K}_{\text {моб }}},
$$


где $\mathrm{K}_{\text {мин }}$ - коэффициент минимизации; $\mathrm{K}_{\text {реал }}$ - коэффициент реалистичности; $\kappa_{\text {моб }}$ - коэффициент мобилизации; $n-$ количество показателей в группе.

Коэффициент минимизации определяется по формуле

$$
\mathrm{K}_{\text {мин }}=\sqrt[3]{\mathrm{K}_{\text {деф.пр }} \cdot \mathrm{K}_{\text {пот }} \cdot \mathrm{K}_{\text {пт }}} \cdot
$$

Коэффициент реалистичности определяется по формуле

$$
\mathrm{K}_{\text {реал }}=\sqrt[3]{\mathrm{K}_{\text {кाп }} \cdot \mathrm{K}_{\text {затр }} \cdot \mathrm{K}_{3.06}} \cdot
$$

Коэффициент мобилизации определяется по формуле

$$
\mathrm{K}_{\text {моб }}=\sqrt[3]{\mathrm{K}_{\text {перс }} \cdot \mathrm{K}_{\text {пат }} \cdot \mathrm{K}_{\text {проф }}} \cdot
$$

Отметим, что расчет каждого показателя для оценки ИТУРпэсмп проводится на основе фактических данных значения показателя на основе аналитической отчетности предприятий, с последующей их трансформацией в относительные величины методом соотношения показателя с максимальным значением в группе анализируемых предприятий [16-18].

Для расчета оценки интегрального коэффициента ИТУРпэсмп предложено использовать среднеарифметическую величину. Поскольку отобранные нами специфические показатели имеют различную размерность, а решение задачи исследования требует их встраивания в единую размерную шкалу, было произведено отображение этих показателей на единую шкалу, в качестве которой был выбран интервал $(0,1)$.

Число специфических показателей и групп показателей зависит от задач, от специфических отраслевых особенностей машиностроительных предприятий, особенностей производственно-хозяйственной деятельности одной отрасли и между отраслями с целью выявления резервов в рамках результативного управления производством.

Коэффициент, характеризующий метод оценки ИТУРпэсмп, интерпретируется исходя из условий: $0 \leq \mathrm{K} \leq 0,4-$ неудовлетворительный; $0,4 \leq \mathrm{K} \leq 0,7-$ удовлетворительный; $0,7 \leq K \leq 0,8-$ хороший; $0,8 \leq \kappa \leq 1,0$ - высокий уровень оценки.

Предложенный метод оценки ИТУРпэсмп был использован для решения практической задачи, связанной с оценкой экономической эффективности ИТУРпэсмп на исследуемых предприятиях г. Перми. Внедрение отдельных составляющих ИТУРпэсмп проводилось на ряде машиностроительных предприятий г. Перми, входящих в отрасль авиационного двигателестроения, участвующих в кооперации, специализирующихся на разработке и выпуске серийного производства деталей двигателей и мотогондол из полимерных композиционных материалов для перспективных авиационных двигателей. Результаты оценки представлены в табл. 4. 
Таблица 4

Оценка экономической эффективности ИТУРпэсмп на исследуемых машиностроительных предприятиях г. Перми

\begin{tabular}{|c|c|c|c|c|c|c|c|c|c|}
\hline \multirow[t]{2}{*}{ Коэффициенты } & \multicolumn{3}{|c|}{$\begin{array}{c}\text { АО «ОДК- } \\
\text { Авиадвигатель» }\end{array}$} & \multicolumn{3}{|c|}{$\begin{array}{c}\text { АО «ОДК- } \\
\text { Пермские моторы» }\end{array}$} & \multicolumn{3}{|c|}{$\begin{array}{c}\mathrm{AO} \ll \Pi 3 \\
\text { «Машиностроитель» }\end{array}$} \\
\hline & 2014 & 2015 & 2016 & 2014 & 2015 & 2016 & 2014 & 2015 & 2016 \\
\hline $\begin{array}{l}\text { Коэффициент } \\
\text { минимизации }\end{array}$ & 0,55 & 0,48 & 0,46 & 0,62 & 0,56 & 0,55 & 0,66 & 0,58 & 0,59 \\
\hline $\begin{array}{l}\text { Коэффициент } \\
\text { реалистичности }\end{array}$ & 0,58 & 0,72 & 0,70 & 0,61 & 0,71 & 0,69 & 0,57 & 0,67 & 0,70 \\
\hline $\begin{array}{l}\text { Коэффициент } \\
\text { мобилизации }\end{array}$ & 0,94 & 1,01 & 1,44 & 0,98 & 1,26 & 1,53 & 1,01 & 1,22 & 1,40 \\
\hline $\begin{array}{l}\text { Коэффициент } \\
\text { ИТУРпэсмп } \\
\end{array}$ & 0,67 & 0,70 & $\mathbf{0 , 7 7}$ & 0,72 & 0,79 & $\mathbf{0 , 8 3}$ & 0,72 & 0,78 & $\mathbf{0 , 8 3}$ \\
\hline
\end{tabular}

Оценка экономической эффективности на исследуемых машиностроительных предприятиях г. Перми за 2016 год АО «ОДК-Авиадвигатель» $($ К - 0,77), АО «ОДК-Пермские моторы» $(К-0,83)$, АО «ПЗ «Машиностроитель» $(К-0,83)$ показывает хороший уровень, что говорит нам о результативности проведенных мероприятий на основе отдельных составляющих интегрированной технологии управления развитием производственно-экономической системы.

Разработанный автором метод позволяет оценить количественные и качественные параметры (объем производства, степень использования производственных ресурсов, качество производимой продукции, длительность производственного цикла, время выполнения заказа, размер производственных запасов) ожидаемого повышения экономической эффективности, полученные в результате внедрения отдельных составляющих ИТУРпэсмп. Эти параметры ввиду отраслевой специфики, специализации и типа производства определяются для каждого конкретного машиностроительного предприятия отдельно.

Таким образом, разработан авторский метод оценки экономической эффективности интегрированной технологии управления развитием производственно-экономической системы, который охватывает финансовую, экономическую, производственную и материально-техническую сферы предприятия. Метод отличается тем, что включает в себя систему специфических показателей, увязанных с принципами ресурсно-процессного подхода и управленческими решениями, вырабатываемыми в данной технологии, который обеспечивает расчет интегрированного показателя эффективности.

\section{Список литературы}

1. Портер М. Международная конкуренция. Конкурентные преимущества стран. - М.: Вильямс, 2002. - 496 с.

2. Акатов Н.Б. Управление переходом к саморазвивающимся инновационным организациям: теория и практика: моногр. - Пермь: Изд-во Перм. нац. исслед. политехн. ун-та, 2012. - 251 с. 
3. Герасимов К.Б. Развитие процесса управления инновационным потенциалом организации // Вестник Волжского университета им. В.Н. Татищева. - 2012. - № 1. - С. 12-19.

4. Молодчик А.В., Молодчик М.А. Менеджмент: стратегия, структура, персонал, знание: учеб. пособие. - М.: Изд. дом ГУ ВШЭ, 2005. - 296 с.

5. Пригожин А.И. Методы развития организаций / МЦФЭР. - М., 2003. $864 \mathrm{c}$.

6. Тис Д. Дж., Пизано Г., Шуен Э. Динамические способности фирмы и стратегическое управление // Вестник СПбГУ. - 2003. - № 4. - С. 47-75.

7. Акатов Н.Б., Попов В.Л., Ташкинов А.Г. Разработка методики оценки эффективности проектов развития производственной системы предприятия в рамках интегральной технологии управления // Экономика и предпринимательство. - 2016. - № 12, ч. 2. - С. 900-907.

8. Пыткин А.Н., Блаженкова Н.М. Взаимосвязь эффективности и результативности деятельности хозяйственной организации // Журнал экономической теории. - 2008. - № 8. - С 133-139.

9. Попов В.Л., Ташкинов А.Г. Ресурсно-процессное управление при развитии производственных систем // Экономика и предпринимательство. 2015. - № 11, ч. 2. - С. 674-677.

10. Попов В.Л., Ташкинов А.Г. Механизм управления изменениями при развитии производственных систем // Экономика и предпринимательство. 2015. - № 12, ч. 3. - С. 757-760.

11. Ёлохова И.В., Малинина С.Е. Современные проблемы оценки экономической эффективности инновационных проектов // Вестник Пермского университета. Экономика. - 2014. - № 3(22). - С. 74-81.

12. Быкова Е.С., Ленина В.В., Шубина Н.Н. Экономика и организация производства на предприятиях машиностроения: учеб. пособие. - Пермь: Изд-во Перм. гос. техн. ун-та, 2007. - 168 с.

13. Миролюбова Т.В., Модорский А.В. Перспективы повышения эффективности предприятий ТЭК в условиях институциональных кризисов // Вестник Пермского университета. Экономика. - 2012. - Вып. 2(13). - С. 52-59.

14. Ташкинов А.Г. Разработка интегрированной технологии управления развитием производственной системы машиностроительного предприятия // Российское предпринимательство. - 2017. - Т. 18, № 19. - С. 2867-2878. DOI: 10.18334/rp.18.19.38357

15. Попов В.Л., Ташкинов А.Г. Совершенствование механизма управления промышленным предприятием // Вестник Пермского национального исследовательского политехнического университета. Социально-экономические науки. - 2016. - № 2. - С. 172-180.

16. АО «Пермский завод «Машиностроитель». Годовые отчеты за 2014, 2015, 2016 гг. [Электронный pecypc]. - URL: http://pzmash.perm.ru (дата обращения: 12.12.2017). 
17. АО «ОДК-Авиадвигатель». Годовые отчеты за 2014, 2015, 2016 гг. [Электронный ресурc]. - URL: http:// http://www.avid.ru/about/activity/ (дата обращения: 12.12.2017).

18. АО «ОДК-Пермские моторы». Годовые отчеты за 2014, 2015, 2016 гг. [Электронный ресурс]. - URL: http://http://pmz.ru/ (дата обращения: 12.12.2017).

\section{References}

1. Porter M. Mezhdunarodnaia konkurentsiia. Konkurentnye preimushchestva stran [International competition. Competitive advantages of the countries]. Moscow, Vil'iams, 2002, 496 p.

2. Akatov N.B. Upravlenie perekhodom k samorazvivaiushchimsia innovatsionnym organizatsiiam: teoriia i praktika [Management of transition to self-developing innovative organizations: theory and practice]. Perm, Perm National Research Polytechnic University, 2012, 251 p.

3. Gerasimov K.B. Razvitie protsessa upravleniia innovatsionnym potentsialom organizatsii [Development of the process of organization's innovation potential management]. Vestnik Volzhskogo universiteta im. V.N. Tatishcheva, 2012, no. 1, pp. 12-19.

4. Molodchik A.V., Molodchik M.A. Menedzhment: strategiia, struktura, personal, znanie [Management: Strategy, structure, staff, knowledge]. Moscow, Higher School of Economics, 2005, 296 p.

5. Prigozhin A.I. Metody razvitiia organizatsii [Methods for company's development]. Moscow, MTsFER, 2003, 864 p.

6. Tis D.Dzh., Pizano G., Shuen E. Dinamicheskie sposobnosti firmy i strategicheskoe upravlenie [Dynamic capabilities of the company and strategic management]. Vestnik SPbGU, 2003, no. 4, pp. 47-75.

7. Akatov N.B., Popov V.L., Tashkinov A.G. Razrabotka metodiki otsenki effektivnosti proektov razvitiia proizvodstvennoi sistemy predpriiatiia $\mathrm{v}$ ramkakh integral'noi tekhnologii upravleniia [Development of a technique of assessing efficiency for projects of development of a corporate production system within integrated management technology]. Ekonomika i predprinimatel'stvo, 2016, no. 12, part 2, pp. 900-907.

8. Pytkin A.N., Blazhenkova N.M. Vzaimosviaz' effektivnosti i rezul'tativnosti deiatel'nosti khoziaistvennoi organizatsii [The interrelation between efficiency and productivity of an economic organization's activity]. Zhurnal ekonomicheskoi teorii, 2008, no. 8, pp. 133-139.

9. Popov V.L., Tashkinov A.G. Resursno-protsessnoe upravlenie pri razvitii proizvodstvennykh system [Resource-process management at development of production systems]. Ekonomika i predprinimatel'stvo, 2015, no. 11, part 2, pp. 674-677. 
10. Popov V.L., Tashkinov A.G. Mekhanizm upravleniia izmeneniiami pri razvitii proizvodstvennykh sistem [The mechanism of management of changes at development of production systems]. Ekonomika $i$ predprinimatel'stvo, 2015, no. 12 , part. 3 , pp. $757-760$.

11. Elokhova I.V., Malinina S.E. Sovremennye problemy otsenki ekonomicheskoi effektivnosti innovatsionnykh proektov [Modern problems of economic efficiency evaluation of innovative projects]. Vestnik Permskogo universiteta. Ekonomika, 2014, no. 3(22), pp. 74-81.

12. Bykova E.S., Lenina V.V., Shubina N.N. Ekonomika i organizatsiia proizvodstva na predpriiatiiakh mashinostroeniia [Economy and the organization of production at the enterprises of mechanical engineering]. Perm, Perm State Technical University, 2007, 168 p.

13. Miroliubova T.V., Modorskii A.V. Perspektivy povysheniia effektivnosti predpriiatii TEK v usloviiakh institutsional'nykh krizisov [Prospects for increasing efficiency of the energy industries enterprises in the conditions of institutional crises]. Vestnik Permskogo universiteta. Ekonomika, 2012, iss. 2(13), pp. 52-59.

14. Tashkinov A.G. Razrabotka integrirovannoi tekhnologii upravleniia razvitiem proizvodstvennoi sistemy mashinostroitel'nogo predpriiatiia [Development of an integrated management technology for the development of the production system of a machine-building enterprise]. Rossiiskoe predprinimatel'stvo, 2017, vol. 18, no. 19, pp. 2867-2878. DOI: 10.18334/rp.18.19.38357.

15. Popov V.L., Tashkinov A.G. Sovershenstvovanie mekhanizma upravleniia promyshlennym predpriiatiem [Improvement of the mechanism of an industrial enterprise management]. PNRPU Sociology and Economics Bulletin, 2016, no. 2, pp. 172-180.

16. AO Permskii zavod Mashinostroitel'. Godovye otchety za 2014, 2015, 2016 gg. [Perm Plant Mashinostroitel. Annual reports for 2014, 2015, 2016], available at: http://pzmash.perm.ru (accessed 12 December 2017).

17. AO ODK-Aviadvigatel'. Godovye otchety za 2014, 2015, 2016 gg. [UEC-Aviadvigatel. Annual reports for 2014, 2015, 2016], available at: http:// http://www.avid.ru/about/activity/ (accessed 12 December 2017).

18. AO ODK-Permskie motory. Godovye otchety za 2014, 2015, 2016 gg. [UEC-Perm Engines.

Оригинальность $81 \%$

Получено 12.04.2018 Принято 03.05.2018 Опубликовано 28.12.2018 


\section{A.G. Tashkinov}

\section{DEVELOPING A METHOD OF COMPETITIVENESS ESTIMATION FOR PRODUCTION-ECONOMIC SYSTEM OF MACHINE-BUILDING ENTERPRISE}

The issues of management technology and methods of its assessment attract much attention of the machine-building enterprise administrators. The Russian machine-building enterprises at the present stage of development carry out intensive search of the solution of economic problems and productive ways to increase profits of economic entities in the competitive environment. The solution of a problem of ensuring competitiveness of economic entities in the conditions of dynamic economy acquires special relevance. That said, creation and realization of flexible productive and economic systems seems to be an appropriate solution of this problem. Most of all, an integrated technology of managing development of productive and economic system meets the requirements imposed. The paper demonstrates that a better competitiveness of machine-building enterprises is possible due to the development and subsequent implementation and assessment of integrated technologies of development management. To manage efficiently a process of transformation the author suggests an integrated technology of managing development of the economic system of machine-building enterprise. The paper presents in details an original method of assessing economic efficiency of the integrated technology of development management, describing its main advantages. In order to assess economic efficiency of the integrated technology of development management a system of specific indicators is offered. The assessment of economic eff $\mathrm{i}$ ciency is carried out by means of specific indicators according to the procedure developed. The latter has been applied in practical task solving at machine-building enterprises of Perm, Russia. The method developed helps to identify the current state of the major factors of the enterprise, capable of providing realization of innovative ideas and design of competitive products and making strategic decisions fostering competitiveness of machine-building enterprises.

Keywords: integrated technology of managing development of productive and economic system of machine-building enterprise, principles of resource-process approach, economic efficiency.

Aleksey G. Tashkinov - Head of the Coordinating Methodological Center for the Implementation of the Digital Economy, Perm plant Mashinostroitel; Postgraduate Student, Department of Management and Marketing, Perm National Research Polytechnic University, e-mail: alekss.perm@gmail.com.

Received 12.04.2018 Accepted 03.05.2018 Published 28.12.2018 